\title{
ENTRE AS RUÍNAS DO PODER: ARTE E CINEMA, GOLPE E ALEGORIA ${ }^{1}$
}

\author{
AMONG THE RUINS OF POWER: ART AND CINEMA, COUP \\ AND ALLEGORY
}

Fernando Simplício dos Santos ${ }^{2}$

O filme de Glauber Rocha, Terra em transe, foi montado em 1966, em pleno contexto das divergências do governo ditatorial. Ironicamente fundamentado nas maravilhas do país "Eldorado", o cenário fílmico configura a imagem de uma sociedade ideal, na qual a revolução e a liberdade, a priori, seriam imprescindíveis. No entanto, a apresentação desse lugar utópico traduz a desestabilização política, econômica e cultural do Brasil e de outros países da América Latina da época (PRADO JÚNIOR, 2007). Assim, tem-se uma reinvenção (crítica e ao mesmo tempo lúdica) do golpe de 64 e da instauração da ditadura militar nacional que não pretende somente burlar a censura, mas também sondar as diversas facetas do regime de exceção para explorá-las em suas possíveis multiplicidades ou mutabilidades histórico-representacionais.

As causas de instabilidade desse país em conflito são especialmente representadas, engajada e poeticamente, pelas recordações do protagonista Paulo Martins: um indivíduo que, a partir de seus devaneios poéticos, pretende criticar e/ ou reconstituir o discurso partidário ditatorial. Contudo, se, por um lado, ele tenta usar toda sua erudição para sublinhar certo ideal revolucionário, por outro, é obrigado a conviver com a impossibilidade de construir uma nação em que as transformações econômicas, políticas e

1 Texto base de ponencia apresentada durante as XII Jornadas Andinas de Literatura Latinoamericana - JALLA, La Paz, em agosto de 2016.

2 Doutor em Teoria e história literária pela Unicamp e professor da Universidade Federal de Rondônia. 
culturais proporcionariam novos rumos para todas as classes da sociedade. Com efeito, esta analogia ajuda-nos a entender melhor o emblema proposto pelo metafórico transe - no filme, estado de aflição e de melancolia que justapõe uma idéia de ordem a uma natureza caótica, condizendo com o próprio clima de tensão e luta do país-alegórico representado por Glauber Rocha.

Tanto em Terra em transe quanto em Lamarca, filme de Sérgio Rezende (1994), baseado na história de vida do general Carlos Lamarca (1937-1971) - que desistiu das patentes militares para se tornar um líder político e capitão de guerrilha - e no livro homônimo (1980) escrito por Emiliano José e Miranda Oldack, pode-se mapear, assim como destaca Peter Burke, o papel do cineasta como historiador que traz à tona uma problematização em torno de dificuldades ocorridas em determinado contexto, de modo a tratar o espectador como uma das testemunhas de certos eventos:

O poder do filme é que ele proporciona ao espectador uma sensação de testemunhar os eventos. Este é também o perigo do medium - como no caso da fotografia instantânea... E o diretor está preocupado não somente com o que aconteceu realmente, mas também em contar uma história que tenha forma artística e que possa mobilizar os sentidos de muitos espectadores (...). O ponto essencial é que uma história filmada, como uma história pintada ou escrita, é um ato de interpretação (BURKE, 2004, p. 200).

$\mathrm{Na}$ adaptação de Rezende, todos os militantes percebem, na figura do ex-soldado, uma chance de conduzi-los à revolução. Sobretudo neste filme, sobressai-se o papel firmado na ação revolucionária, mesmo que também trate da impossibilidade de constituir a reestruturação das instâncias governamentais.

$\mathrm{Na}$ esteira das considerações expostas, o objetivo deste trabalho é analisar o filme Terra em transe, a fim de averiguar como a figura do intelectual latino-americano é representada em face das incoerências do autoritarismo; analisar o motivo por que o enredo de Rocha pode exemplificar conflitos eclodidos em nosso continente, destacando-se no contexto do cinema nacional do período. Nesse sentido, propõe-se uma comparação com as cenas finais do citado filme Lamarca. 
Na década de 60, o programa político do presidente brasileiro João Goulart (1918-1976), denominado "Janguismo", permitia a composição de uma arte revolucionária, a qual reivindicava, sobretudo, as reformas agrárias, urbanas e econômicas (CHIAVENATO, 2010). Claro que isso contribuía para acentuar, ainda mais, a ideologia comunista. Todavia, a burguesia brasileira, os adeptos do imperialismo norte-americano e vários setores do exército decidiram depor o presidente, instaurando o golpe de 1964. Mesmo sabendo da existência de tal estratégia política, Goulart fez pouca coisa para impedi-la, porque acreditava numa organização de bases populares que o apoiaria e venceria os seus opositores. Porém, sem armas e apenas baseada na ideologia comunista, não foi possível concretizar o sonho da revolução.

Uma das nossas hipóteses básicas considera que, ao elaborar Terra em transe, Glauber Rocha apresentou a sua interpretação da desestruturação do Brasil da época, entrelaçada às discrepâncias históricas, políticas e culturais que ocorreram na América Latina. De seu lado, a alegoria considerada como um mecanismo analítico colabora para averiguar como a original e lúdica crítica de Rocha é instituída. Aqui, tal questionamento está correlacionado ao próprio projeto do Cinema Novo e à crise do populismo, desencadeada no contexto em que o filme foi elaborado. É a partir desta perspectiva que, por exemplo, Ismail Xavier, no seu livro Alegorias do subdesenvolvimento: cinema novo, tropicalismo, cinema marginal, (1993), considera a alegoria como um conceito crítico e, a um só tempo, inovador e revelador.

Em Terra em transe, são apresentadas as paisagens do país Eldorado junto a célebres figuras da História do Brasil e da América Latina: como as do político e do imperador; do padre e do índio. Ainda que esteja implícita a elaboração comparativa dessas imagens, além de destacar a diversidade cultural, alude ao secular "confronto de classes". ${ }^{3}$ Os dois primeiros, efetivos membros do desenvolvimento social, econômico e cultural das nações latino-americanas, usavam um discurso progressista que, na verdade, visava à obtenção de lucro e à conquista do poder político - mesmo que para

3 Em Terra em transe, entre outros, os personagens são: o poeta Paulo Martins, interpretado pelo ator Jardel Filho; Dom Porfírio Diaz, pelo ator Paulo Autran; Vieira, por José Lewgoy; Sara, pela atriz Glauce Rocha; Julio Fuentes, pelo ator Paulo Gracindo; Sílvia, por Danuza Leão; Álvaro, por Hugo Carvana. 
isso precisassem aniquilar as civilizações Inca e Asteca, por exemplo. Já os representantes da igreja diziam que sua função era a de instaurar a fé cristã no Novo Mundo. Mas, à medida que foram catequizando os indígenas, o clero também colaborou com o aniquilamento de tribos, ajudando os europeus na exploração rendosa dos bens naturais e na destruição de boa parte das representações culturais nativas.

No filme de Rocha, no momento em que as ambivalências políticas são comparadas com os sentimentos comuns ao ser humano, tais como: as aflições, o medo e as dúvidas, o populista Vieira destaca peculiarmente tanto as incoerências de seu sistema político, quanto às próprias angústias do poeta e jornalista Paulo Martins: homem dividido entre a humanização e o poder. Assim, questões políticas versus questões de natureza existencial e filosófica aparecem sobrepostas. Em face às discrepâncias do discurso governamental tal protagonista emocionalmente se desestabiliza e entra em transe.

Alvejado no começo da história pelos soldados do exército, minutos antes de morrer, Paulo vislumbra inúmeras imagens que compõem e dinamizam anacronicamente toda a trama do filme. A partir da análise da relação entre representação e memória, assim como é sugerida pela teoria de Padrós, pode-se dizer que essas imagens configuradas na mente conturbada do protagonista são reconstituídas pelas "lembranças da memória [que] no tempo inventam e descobrem novos fatos sem condições de enfrentar a aferição lógica dos mesmos" (PADRÓS, 2001, p. 82). Além disso, em Terra em transe, a técnica da elaboração da narrativa fílmica está acoplada à fragmentação, remetendo-se, portanto, ao sentido benjaminiano do termo. Vinculada à determinada crítica, denuncia, a um só tempo, sistemas estatais que fundam uma "política do esquecimento", bem como reconfigura as maneiras tradicionais de se compor uma obra artística.

Assim, também é possível relacionar a técnica de elaboração dos diálogos da construção cinematográfica de Glauber Rocha àquilo que Rosset denomina de ilusão: a qual consiste em duplicar um fato "real" ou uma coisa, "como a técnica do ilusionista, que conta com o mesmo efeito de deslocamento e de duplicação da parte do espectador: enquanto 
se ocupa com a coisa, dirige o seu olhar para outro lugar, para lá onde [aparentemente] nada acontece ${ }^{4 \prime}$ (ROSSET, 2008, p. 23). No caso de Terra em transe, tudo isso está em contato com algo transcendente que é perceptível, sobretudo, ao visionário poeta. Em meio aos seus derradeiros delírios, ele insiste em retraçar certos caminhos de sua história de vida:

$\begin{array}{ll}\text { Vejo campos de agonia } & \begin{array}{l}\text { A morte nos construindo, } \\ \text { velejo os mares do não }\end{array} \\ \text { florindo, devorando. } \\ \text { nanta da minha espada } & \text { Convivemos com a morte. } \\ \begin{array}{l}\text { que herdei daquelas guerras, } \\ \text { umas de mais, outras de menos, ao passo que vamos, recuamos (ROCHA, 1966, 16: 28). }\end{array} & \text { em derrota do quanto empregamos, } \\ \begin{array}{ll}\text { testemunhas enclausuradas } \\ \text { do sangue que nos sustenta. }\end{array}\end{array}$

Como um sonho efêmero, sequências de versos difundem-se por vários trechos de Terra em transe. E, embora sejam declamadas no momento da cena em foco, em outras circunstâncias, trata-se da vOz do homem que perscruta o seu passado, buscando uma interpretação plausível para suas derrotas, mesmo que não consiga concretizar tal exercício. $O$ transe aparece interligado à passagem vertiginosa que demarca os limites entre a morte e a vida; a arte e a política.

Metaforicamente, os "mares do não" são as veredas que arrastam Paulo Martins para além do patamar terrestre e concomitantemente trazem à sua mente várias figurações turvas. Seu estado melancólico condiz com um aspecto particular da crise do sujeito moderno, pois suas reminiscências podem ser vinculadas ao "souvenir benjaminiano", concebido como alegoria de um raro legado passadista, isto é, segundo Bolle, “'como se fosse um conjunto de bens mortos' - lembranças de uma experiência morta” (BOLLE, 1994, p. 132). Estando tudo isso relacionado ao referido flasbback, outro objetivo da trama é refletir sobre as incoerências do autoritarismo e os efeitos indeléveis que elas causaram na sociedade ou na própria vida do poeta.

No texto "História como alegoria", Peter Burke chama a nossa atenção para a formulação histórica de uma cadeia de associações que,

4 No filme, a técnica que tende a desviar a perspectiva "para outro lugar" diz respeito à comparação entre poesia e política. 
através dos tempos, é atinente à Bíblia e à trajetória de Jesus Cristo. Nesse sentido, ele observa que

A interpretação linear dominante da história coexiste com a admissão da reencenação. No Velho Testamento, Josué, por exemplo, é apresentado como um novo Moisés, e assim também o é Elias. No Novo Testamento, a idéia de replay informa os Atos dos Apóstolos, os quais são regularmente descritos como revivendo a vida, a morte e a ressurreição de Cristo (BURKE, 1995, p. 201).

Historicamente, sabe-se que tal reinterpretação é recorrente. Porém, nos filmes Terra em transe e em Lamarca, não se trata de tomar literalmente a história de Cristo e reencená-la em um contexto de luta revolucionária. Trata-se de sondar semelhanças que, mesmo com o passar dos séculos, se repetem potencial e artisticamente. Segundo Burke, esta característica está interligada à alegoria mistica ou metafísica. Sua função é destacar uma forma de representação muito expressiva: a que "assume alguma espécie de conexão oculta ou invisível entre dois indivíduos ou eventos discutidos, por mais separados que estejam no espaço ou no tempo" (BURKE, 1995, p. 201).

Alegoricamente, a morte de Paulo Martins pode ser igualada à de outras pessoas que também enfrentaram tiranias e regimes ditatoriais. Não obstante, não deixa de elucidar a vitória do moderno Estado de exceção, do qual inicialmente o próprio poeta fazia parte. Isso porque ele desistiu de seguir a carreira política ao lado do senador Dom Porfírio Diaz fim de tornar-se um dos oponentes do poder, sobretudo por meio de sua poesia engajada. Mesmo assim, no momento em que ele compreende as dificuldades de pôr em prática os seus ideais (ROCHA, 1966, 26: 32), percebe a impossibilidade de modificar uma sociedade regida pelo autoritarismo. Daí a morte ser transformada em um símbolo da própria desilusão ou da derrota.

Ao passo que a morte do poeta parece ser sem propósito (ROCHA, 1966, 1: 43: 32), o papel do mártir é deslocado e colocado em xeque, pois não representa mais a figura de um revolucionário que, com sua punição, libertaria um povo de seu sofrimento e exploração. No filme, é o soberano

5 Segundo Glauber Rocha, personagem inspirado no político Carlos Lacerda. Cf. documentário, In: CD 02, 2006. 
e o tirano que se transforma em "salvador"; é assim que o senador Dom Porfírio Diaz se torna um pastiche do próprio ditador latino-americano. Para ele, o exercício político é reciprocamente considerado como função religiosa: espécie de sacerdócio baseado na trajetória de Jesus Cristo (ROCHA, 1966, 11: 25).

À sua maneira, Lamarca também apresenta o fim trágico daquele que poderia libertar a sociedade e conduzi-la à revolução. Esta adaptação de Sérgio Rezende problematiza certo tipo de comunismo-messiânico, ressaltando, com contundência, a impossibilidade de, a partir da luta armada contra o governo ditatorial, modificar os rumos da história nacional.

No desfecho de Lamarca, tem-se a cena do assassinato do ex-militar, ocorrido em 1971, nos sertões da Bahia. Aqui, a alusão aos mártires da história chega a tal ponto que, presentes a morrer, o corpo do ex-capitão é posto como o de Cristo ao ser crucificado. A imagem do redentor aparece vinculada à do homem que solitariamente expira sem as honras da vitória. As últimas palavras expressas no filme Lamarca são "viva a revolução!". Contudo, refletindo sobre a história do Brasil, qual revolução? Uma vez que em nosso contexto seria difícil considerá-la no sentido de transformação das instâncias econômicas, políticas e culturais. A adaptação de Rezende faz menção às inúmeras insurreições que, desde o período colonial, assombram o povo brasileiro. Por outro lado, sabe-se que, no geral, praticamente todas foram malogradas. Se, em Terra em transe, Diaz vale-se da figura do mártir para legitimar soberanamente seu poder, em Lamarca, a morte do ex-combatente do exército está configurada de modo a sublinhar a redenção daqueles que morreram em prol da revolução. De qualquer forma, em ambos os roteiros, a história dos mártires nacionais é, simples e contraditoriamente, transformada em símbolo da própria derrota.

Tanto em Terra em transe, como em Lamarca, as consequências acarretadas pelo governo autoritário traduzem alegoricamente a derrota de toda uma geração de militantes de esquerda; registram o fim de quaisquer tipos de nacionalismos revolucionários; criam e recriam formas de tiranias que, ad aeternum, liquidam a humanidade: - simbolizada, em Terra em transe, pela morte do poeta Paulo Martins; e em Lamarca, pelo assassinato daquele que iria salvar o povo. 
Não foi sem motivo que, com o objetivo de estudar e comparar os aspectos do Estado de exceção moderno com a tirania antiga, Benjamin analisou a Origem do drama Barroco alemão (século XVII). Se em Lamarca, a imagem daquele que é crucificado traduz a impossibilidade da revolução, em Terra em transe, a imagem da morte de Paulo Martins, sobrepostas à coroação de Porfírio Diaz (ROCHA, 1966, 1: 41: 08), representa a força do antigo absolutismo igualada à supremacia do autoritarismo moderno. Tais cenas e formas discursivas têm o poder de problematizar questões de cunho social, cultural, estético e político, dialogando e questionando, até hoje, mecanismos autoritários, inclusive do Brasil contemporâneo. Eis a visão atual, profunda e crítica ainda presente nos dois filmes.

\section{Referências}

AVELAR, I. Alegorias da derrota: a ficção pós-ditatorial e o trabalho do luto na América Latina. Trad. Bras. Saulo Gouveia. Belo Horizonte: Editora da UFMG, 2003.

BENJAMIN, W. Magia e técnica, arte e política. Trad. S. P. Rouanet. 7. ed. São Paulo: Brasiliense, 1994.

BOLLE, W. A Fisiognomia da Metrópole Moderna: Representação da Metrópole em Walter Benjamin. São Paulo: Editora da Universidade de São Paulo, 1994.

BURKE, P. "História como alegoria", In: Estudos Avançados. Universidade de São Paulo - USP, 1995, n. 25, pp. 197-212.

BURKE, P. Testemunha ocular: história e imagem. Trad. V. M. Xavier dos Santos. Bauru (SP): Edusc, 2004.

Chiavenato, J. J. O golpe de 64 e a ditadura militar. 2. ed., São Paulo: Moderna, 2010.

JOSÉ, E; OLDACK, M. Lamarca: o capitão da guerrilha. São Paulo: Global, 1989.

PADRÓS, E. S. "Usos da memória e do esquecimento na História”, In: Letras, Santa Maria, 2001, n. 22, pp.79-95.

PRADO JÚNIOR, C; FERNANDES, F. Clássicos sobre a revolução brasileira. São Paulo: Expressão Popular, 2007.

REZENDE, S. (Produtor). REZENDE, S. (Diretor). [Película cinematográfica]. Lamarca. Brasil. Estúdio: Riofilme, 1994.

ROCHA, G. (Produtor). ROCHA, G. (Diretor). [Película cinematográfica]. Terra em transe. Brasil. Estúdio: Grupo Novo de Cinema e TV, 2006.

ROSSET, C. O real e seu duplo: ensaio sobre a ilusão. 2. ed. Trad. José Thomaz Brum, Rio de Janeiro: José Olympio, 2008. 
XAVIER, I. Alegorias do subdesenvolvimento - Cinema Novo, Tropicalismo, Cinema Marginal. São Paulo: Brasiliense, 1993.

Data de recebimento: $05 / 11 / 2018$

Data de aceite: $28 / 12 / 2018$ 